AperTO - Archivio Istituzionale Open Access dell'Università di Torino

\title{
ACG Clinical Guideline on Crohn's Disease: A Point of View from Europe
}

\section{This is a pre print version of the following article:}

Original Citation:

Availability:

This version is available http://hdl.handle.net/2318/1701124

since 2019-05-07T17:06:15Z

Published version:

DOI:10.1038/s41395-018-0410-3

Terms of use:

Open Access

Anyone can freely access the full text of works made available as "Open Access". Works made available under a Creative Commons license can be used according to the terms and conditions of said license. Use of all other works requires consent of the right holder (author or publisher) if not exempted from copyright protection by the applicable law. 
ACG Clinical Guideline on Crohn's Disease: A Point of View from Europe

Running Head: Crohn's Disease Management

Davide Giuseppe Ribaldone, MD ${ }^{1}$

${ }^{1}$ Division of Gastroenterology, Department of Medical Sciences, Molinette Hospital, University of Turin, Italy

Corresponding author: Davide Giuseppe Ribaldone, Department of Medical Sciences, Division of Gastroenterology, Università di Torino, C.so Bramante 88 10126 Turin - Italy. E-mail: davrib_1998@yahoo.com Tel: +390116333918, Fax: +390116333623 .

word count: 425

Keywords: Non-Steroidal Anti-Inflammatory Drug; Biosimilars; Magnetic Resonance Enterography

\section{CONFLICT OF INTEREST/STUDY SUPPORT:}

1. The author acting as the submission's guarantor is Davide Giuseppe Ribaldone

2. Davide Giuseppe Ribaldone conceived and written up the paper; he has approved the final draft submitted.

3. No financial support to declare.

4. Conflict of interest: none to declare. 
To the Editor: I have read with great interest the new edition of ACG guidelines on Crohn disease (CD) (1). Most of the statements are immediately applicable not only in the United States, but also in Europe.

There are however some small but important differences in the management of these patients in Europe.

Regarding the diagnostic methods, the authors focused mainly on Computed tomography enterography (CTE) and magnetic resonance enterography (MRE). In Europe bowel ultrasonography is a widely used diagnostic method that has shown to have a comparable diagnostic accuracy, with a lower cost and no radiation emission (the latter feature compared to CTE) (2). If bowel ultrasonography is not widespread in the USA, it would be interesting to know why.

Regarding the factors that can influence the course of the disease, the authors concluded that there are no studies on CD concerning the use of selective cyclooxygenase-2 inhibitors (Coxibs) and that in a short-term therapy they have not shown to cause exacerbation of ulcerative colitis. An European meta-analysis found that gastrointestinal symptoms appear in most cases after a few days of use of Coxibs, and that the risk of worsening intestinal symptoms can occur mainly in patients with an active intestinal disease (3). Therefore, a possible strategy could be a careful follow-up of patients with inactive IBD during the first few days of treatment with Coxibs, due to a possible intestinal relapse, but in patients with a good tolerance in the first two weeks, a long- term therapy could be feasible (up to three months). Finally, the authors have dedicated a paragraph to biosimilar anti-TNF agents. They have mentioned a randomized, non-inferiority phase 4 research on patients affected by $C D$, ulcerative colitis, spondyloarthritis, rheumatoid arthritis, psoriatic arthritis, and plaque psoriasis showing that switching from infliximab originator to CT-P13 (biosimilar) was not worsening the course of the disease more than continuing with 
the originator (4). A letter from Europe commenting on the research emphasized that the results on $C D$ itself are emblematic of the statistical problems associated with this study: among the 175 patients with $C D$, the risk of disease worsening was $-14.3 \%$, close to the $15 \%$ non-inferiority margin, and the risk would have exceeded $15 \%$ if the results of the most rigorous intention-to-treat statistical analysis had been reported instead of the per-protocol analysis (5). Furthermore, the authors (4) themselves pointed out that the study did not have sufficient statistical power to show noninferiority in individual pathologies (i.e. CD). It would be interesting to know more comments on a hot topic like that of the efficacy of biosimilars.

\section{REFERENCES}

1. Lichtenstein GR, Loftus E V, Isaacs KL, et al. ACG Clinical Guideline: Management of Crohn's Disease in Adults. Am. J. Gastroenterol. 2018;113:481-517.

2. Bhatnagar G, Stempel C Von, Halligan S, et al. Utility of MR enterography and ultrasound for the investigation of small bowel Crohn's disease. J. Magn. Reson. Imaging 2017;45:1573-1588.

3. Ribaldone DG, Fagoonee S, Astegiano M, et al. Coxib's Safety in Patients with Inflammatory Bowel Diseases: A Meta-analysis. Pain Physician 2015;18:599607.

4. Jørgensen KK, Olsen IC, Goll GL, et al. Switching from originator infliximab to biosimilar CT-P13 compared with maintained treatment with originator infliximab (NOR-SWITCH): a 52-week, randomised, double-blind, noninferiority trial. Lancet 2017;389:2304-2316.

5. Ribaldone DG, Saracco GM, Astegiano M, et al. Efficacy of infliximab biosimilars in patients with Crohn's disease. Lancet 2017;390:2435-2436. 
